\title{
EFFECTS OF LEADING EDGE PROTUBERANCES ON THE AERODYNAMIC PERFORMANCE OF 2D CAMBERED AIRFOIL
}

The pressure and lift coefficients were measured for airfoils with leading edge protuberances in a subsonic wind tunnel and compared with the performance of a baseline NACA 4415 airfoil with a straight leading edge. These protuberances of 2D airfoil mimic the leading edge configuration of the flippers of a humpback whale. Wavelengths were varied from $25 \%$ to $50 \%$ of the chord length whilst amplitude was varied from 5\% to 12\% of the chord length of the baseline. Surface flow visualisation using kaolin was also performed to further analyze the flow patterns and surface swirls and vortices were observed. The presence of protuberances enhanced the stall characteristics of the baseline and low amplitude protuberances exhibited the maximum lift coefficient. However, at low angles of attack, the performance of the modified airfoils is similar to that of the baseline.

\author{
Nomenclature \\ $c$ mean chord length, $\mathrm{cm}$ \\ $s$ span, $\mathrm{cm}$ \\ Re Reynolds number \\ $\mathrm{Cl}$ lift coefficient \\ $C p$ pressure coefficient \\ $\alpha$ angle of attack, degrees
}

\section{Introduction}

Nature benefits us with its ecosystem services and natural systems. Thus one of the inspirations from nature is in the field of biomimetics or bio mimicry. Adaptations from the nature discussed are the tubercles found on the leading edge of humpback whale flippers. These tubercles help them to glide easily through the ocean. This form of adaptation for airfoils has resulted in an increase in their performance. According to Hansen and Kelso et al [1] an airfoil model with such leading edge tubercles achieved higher lift coefficient and large stall angle with minimum drag when compared to the conventional smooth leading edge model.

Experiments carried out by Johari et al [2] and Watts and Fish [3] also showed increase in the lift and a reduction in the drag on the wing with leading edge tubercles. However, all studies by [1], [2] and [3] concluded that there was no significant improvement in the performance in the airfoils at low angles of attack with leading edge tubercles. The previous studies carried out as mentioned above, were conducted for symmetric airfoils and in water. Thus, the primary objective of this study is to investigate the pressure distribution resulting from the leading edge tubercles on 2D
NACA 4415 cambered airfoil models with varying amplitudes and wavelengths in air, along with the measurement of the lift force using a three component balance. Flow visualization using a mixture of kerosene and china clay was also performed to further analyze the flow patterns.

\section{Experimental technique}

For the purpose of the study, four 2D models were manufactured from MDF wood, which included the normal NACA4415 airfoil or the baseline airfoil having the conventional straight leading edge and three other modifications of the baseline airfoil having leading edge sinusoidal protuberances. These three models had the following varying amplitude and wavelength:

Model specifications

Tab. 1

\begin{tabular}{|c|c|c|}
\hline Wing configuration number & Wavelength & Amplitude \\
\hline 1 & $0.25 \mathrm{c}$ & $0.12 \mathrm{c}$ \\
\hline 2 & $0.50 \mathrm{c}$ & $0.05 \mathrm{c}$ \\
\hline 3 & $0.50 \mathrm{c}$ & $0.12 \mathrm{c}$ with flat trough \\
\hline
\end{tabular}

All the experimental models, including the baseline, had an equivalent span of $30 \mathrm{~cm}$ and a chord length of $20 \mathrm{~cm}$. Pressure taps were drilled perpendicular to the local chord position along the upper and lower surfaces of the models. The pressure was transferred to the measurement systems through the help of internally fixed copper and plastic tubes.

\footnotetext{
* Abeer Mukhtar, Humera Golandaz, Young Hwan Kim

Emirates Aviation College, Dubai, United Arab Emirates, E-mai: aby_51@hotmail.com
} 
For measuring the lift force, the surface drilled holes, were filled and the surface was re-polished again for the measurement of lift force.

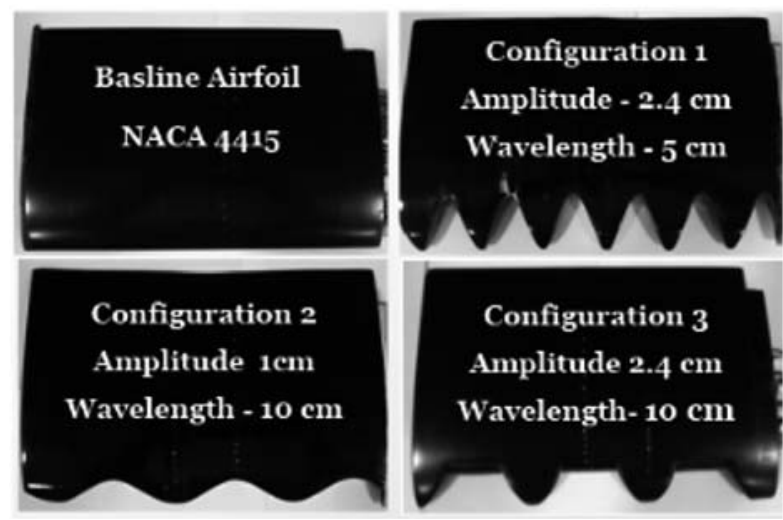

Fig. 1 Experimental models used for the research

For the measurement of the pressure distribution and the lift force, the experiments were carried out at Emirates Aviation College Aerodynamics Lab using an AF100 Subsonic Wind Tunnel. The lift force was measured using a three-component balance. The testing was carried out for $R e=3.5 \times 10^{5}$ and the angle of attack was varied within the range $-3 \leq \alpha \leq 25$ degrees. Surface flow visualization was carried out to further analyze the flow. A mixture of china clay powder with kerosene of the ratio 1:10, i.e. $100 \mathrm{ml}$ of china clay per 1 liter of kerosene, also known as kaolin, was prepared and spread over the surface of the models and the visualization was carried out for the post-stall region $\alpha=18 \mathrm{deg}$ for $R e=3.5 \times 10^{5}$

\section{Results and analysis}

\subsection{Chord-wise pressure coefficient distribution curves}

From the pressure measurements obtained through the wind tunnel testing, a pattern was observed in the manner the pressure coefficient was distributed over the peaks and troughs of the configurations with leading edge protuberances in the post-stall region.

For the baseline model, the upper surface is covered with a negative pressure coefficient while, for the modified models, negative pressure coefficient is obtained near the leading edges of the peak. Adverse pressure gradient is however created as we move further away from the peak in the upper surface. On the other hand, the lower surface of the peaks is dominated by positive pressure coefficients along the entire chord length.

\subsubsection{Baseline and configuration 1:}

In the post-stall region, configuration 1 shows deterioration in the performance compared to the baseline. The baseline model shows a much higher negative pressure coefficient for the upper surface and positive pressure coefficient for the lower surface in Fig. 2
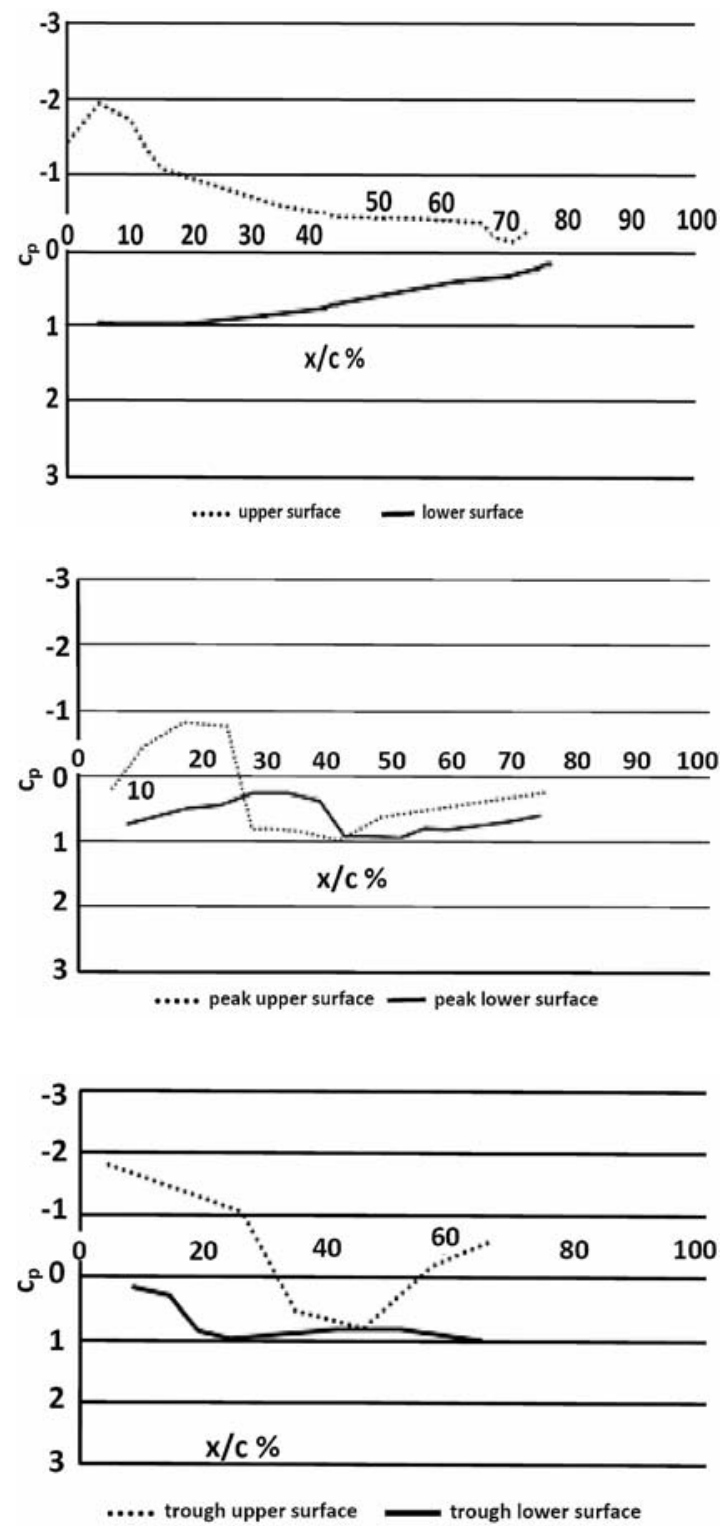

Fig. 2 Comparison between baseline (top centre) and Configuration 1: Peak (bottom left) and Trough (bottom right) at $R e=3.5 \times 10^{5}$

\subsubsection{Baseline and configuration 2:}

In the post-stall region, the peaks in the upper surface exhibit lower negative pressure coefficients, but the troughs a higher negative pressure coefficient distribution on the upper surface and higher positive pressure coefficient for the lower surface. 

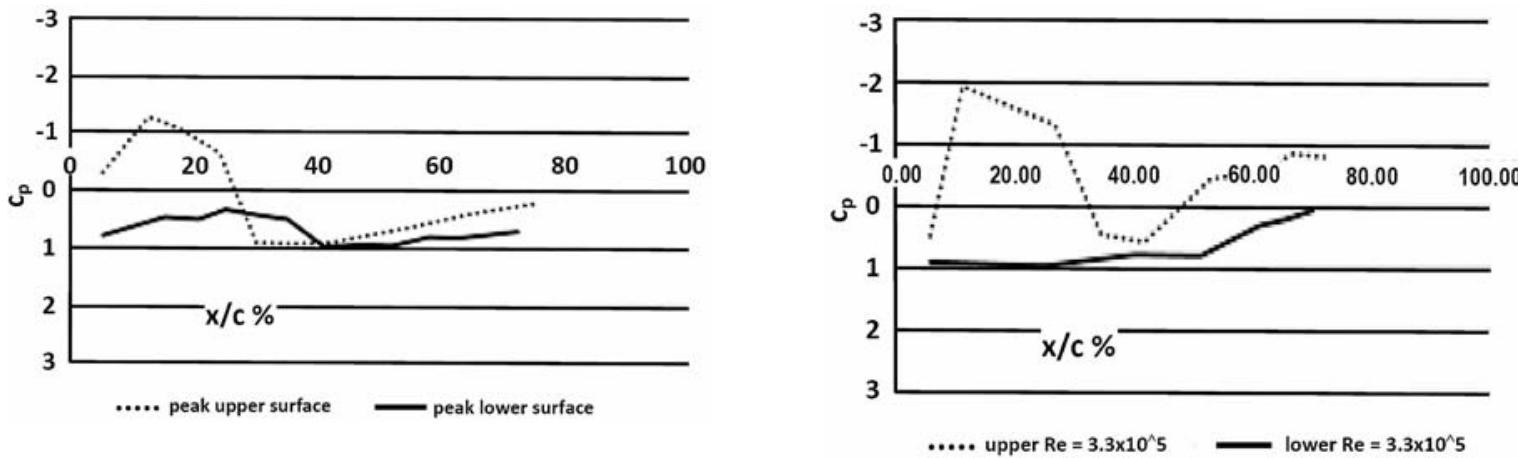

Fig. 3 Configuration 2: Peak (left) and Trough (right) at Re $=3.5 \times 10^{5}$
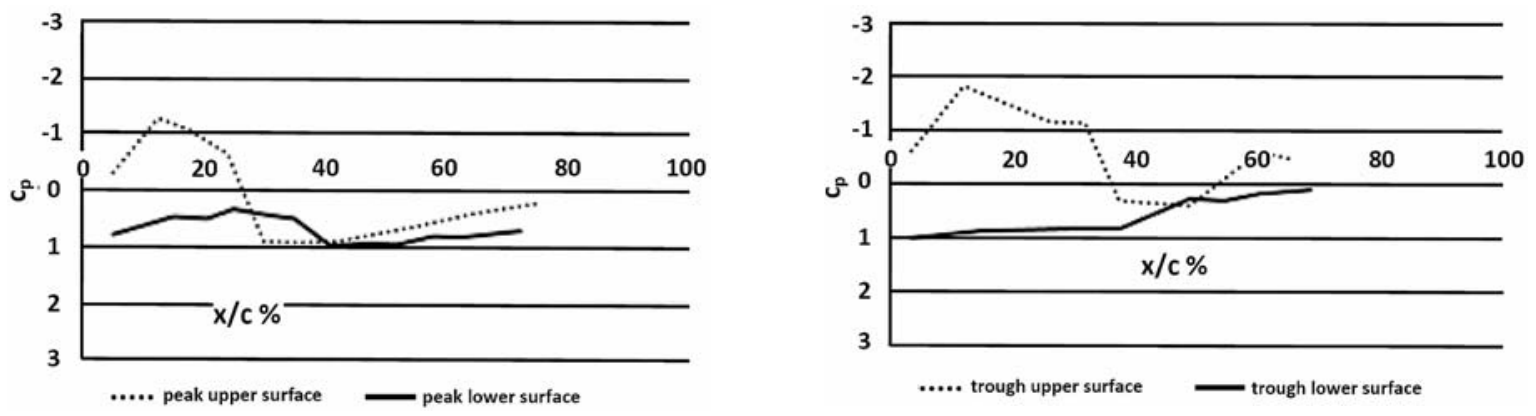

Fig. 4 Configuration 3: Peak (left) and Trough (right) at Re $=3.5 \times 10^{5}$

Thus, the troughs of the configuration 2 significantly improve the pressure distribution for better lift characteristics as compared to configuration 1 as exhibited in Fig. 3

\subsubsection{Baseline and configuration 3:}

As observed in Fig. 4, configuration 3 also shows deterioration in the performance in the post-stall region as the baseline possesses higher negative and positive pressure coefficients for the upper and lower surfaces respectively.

\subsection{Lift coefficient}

The lift force measured is presented below in Fig. 5 using the non-dimensional lift coefficient versus angle of attack for all the tested airfoils. The lift coefficient curve shows that the modified airfoils with leading edge protuberances improve the stall characteristics of the airfoil. The stall is delayed significantly for the modified leading edges compared to the baseline model.

Even though the presence of leading edge protuberances does not enhance the performance at low angles of attack, the maximum lift coefficient achieved is higher than that of the baseline. Configuration 2 obtained a maximum lift coefficient of 1.32 compared to 1.09 for the baseline, thereby increasing the maximum lift coef- ficient by $17.4 \%$ and increased the stall angle of attack by an increase of $28.5 \%$.

While analyzing the three modified leading edges, it can be shown that protuberances with low amplitude perform better than those with high amplitude. Configuration 2, as such, exhibited the most enhancements in terms of lift coefficient amongst the modified airfoils.

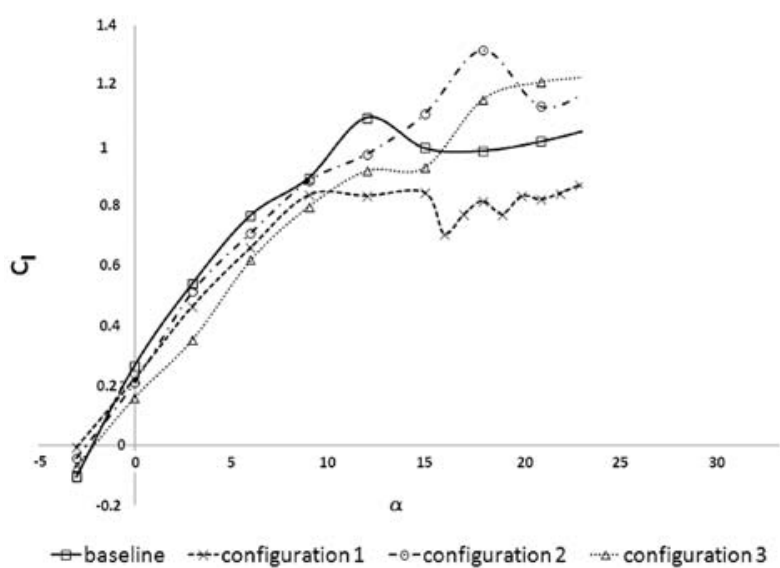

Fig. 5 Lift coefficient Vs Angle of attack (degrees) at $R e=3.5 \times 10^{5}$ 
Conclusion for $R e=3.5 \times 10^{5}$

Tab. 2

\begin{tabular}{|c|c|}
\hline Airfoil & Stall Angle (degrees) Range \\
\hline Baseline NACA 4415 & $12 \leq \alpha \leq 15$ \\
\hline Configuration 1 & $16 \leq \alpha \leq 18$ \\
\hline Configuration 2 & $19 \leq \alpha \leq 21$ \\
\hline Configuration 3 & $27 \leq \alpha \leq 30$ \\
\hline
\end{tabular}

\subsection{Flow visualization}

As seen below (Fig. 6), leading edge flow separation was observed for the baseline model in the post-stall angle of 18 degrees. Separation bubbles were also observed or the baseline model and the separation and re-attachment lines, due to the presence of the separation bubbles, can be clearly observed. For configuration 1 , a very different flow pattern was obtained at the same post-stall angle. Streamline vortices were created at the tips of the peaks near the leading edge which delayed the flow separation behind the peaks. However, behind the troughs, reverse flow due to flow separation was observed. These vortices were created due to the sharp edges of the peak which resulted in the flow being unable to follow the airfoil pattern. Configuration 2 exhibited highly three dimensional flows, where, span wise flow was also created. Swirls can be observed arising from the peak of the upper surface. This could be attributed to the relatively higher pressure of flow over the peak compared to the flow pressure over the trough. Flow separation was observed for Configuration 3 at the edges of the leading edge of the trough. It can be concluded that the protuberances (peak) delays the flow separation.

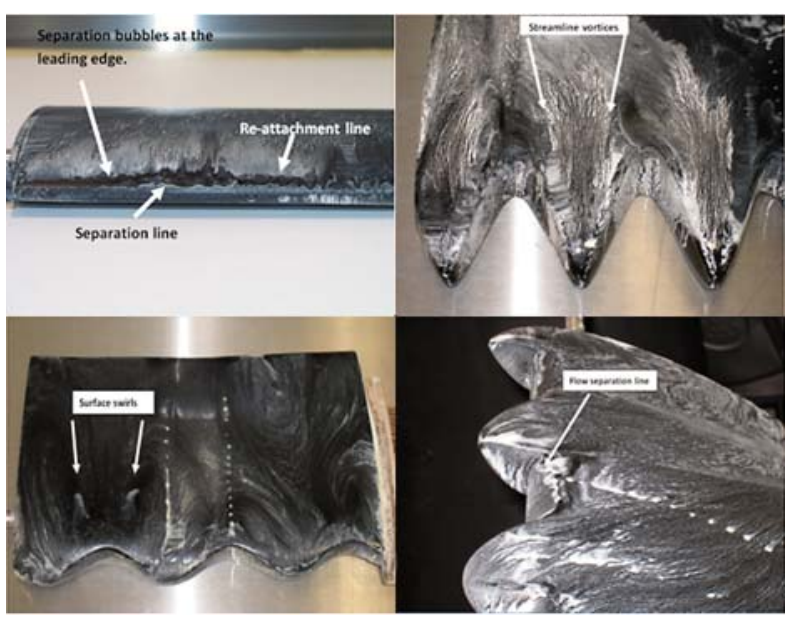

Fig. 6 Flow visualization of the models at 18 degrees angle of attack and $R e=3.3 \times 10^{5}$. Baseline (top left) Configuration 1 (top right) Configuration 2 (bottom left) and Configuration 3 (bottom right)

\section{Conclusion}

A set of 2D NACA 4415 cambered airfoils having leading edge protuberances was tested in a subsonic wind tunnel. The effect of these leading edge protuberances, which mimic the protuberances on the flipper of the humpback whale, was analyzed for $-3 \leq$ $\leq \alpha \leq 25$ degrees and $R e=3.5 \times 10^{5}$ and compared with the performance of the baseline NACA 4415 model having the conventional straight leading edge. From the testing carried out, it was concluded that leading edge protuberances prominently improves the aerodynamic performance of $2 \mathrm{D}$ cambered airfoils in the poststall region. The stall angles for all the modified leading edges were significantly delayed. The stall angle of attack was delayed by $28.5 \%$ and the maximum lift coefficient was increased by $17.4 \%$ for the protuberances with low amplitude as compared to the baseline model. On the other hand, the leading edge protuberances with high amplitude did not enhance the aerodynamic performance for any angle of attack. Although the models with the leading edge protuberances showed a decrease in the performance at low angles of attack, the presence of leading edge protuberances enhances the performance at high angles of attack.

Surface visualization illustrated that for the baseline model, the flow separated at the leading edge in the post-stall region with the formation of separation bubbles. However, for the models with the leading edge protuberances, the flow remained attached for a major portion of the chord length over the peaks with flow separation occurring in the troughs. Thus, the presence of leading edge protuberances improves the stall characteristics of $2 \mathrm{D}$ cambered airfoils by modifying the flow separation patterns and enhances the maximum lift coefficient for low amplitude protuberances at high angles of attack.

The results achieved are in accordance with previously carried out research for airfoils with leading edge protuberances which also proved that the presence of leading edge protuberances enhances the stall characteristics and improves the lift performance in the post- stall region. Based on the results achieved, the application of such leading edge protuberances can be utilized to enhance the performance of wind turbine blades and for low speed UAVs.

\section{Acknowledgement}

This research has been assisted by the works of Acrylic Extreme Production. L.L.C, Dubai, Arabian Wood Factory, Dubai and Dufco Interior works, Dubai in manufacturing the airfoils and delivering the materials for the accomplishment of the research project. The relentless support of our research supervisor, Dr. Young Hwan Kim, and the faculty members of the Aeronautical Engineering Department of Emirates Aviation College, is highly appreciated. 


\section{References}

[1] HANSEN, K., KELSO, R., DALLY, B.: Three Dimensional Effects on the Performance of the Tubercles at the Low Speed Reynolds Numbers. Adelaide, Australia, 2010.

[2] JOHARI, H., HENOCH, C., CUSTODIO, D., LEVSHIN, A.: Effects of Leading-edge Protuberances on Airfoil Performance. AIAA, 2007.

[3] FISH, P. W.: Influence of Leading Edge Tubercles on Wing Performance.

\section{Uncited references}

[4] SELIG, M., DETERS, R., WILliAMSON, A.: Wind Tunnel Testing Airfoils at Low Reynolds Number. Florida, 2011.

[5] HANSEN, K., KELSO, R., DALLY, B.: Performance Variations of Leading-edge Tubercles for Distinct Airfoil Profiles. AIAA, 2011.

[6] MIKLOSOVIC, D., MURRAY, M., HOWLE, L.: Experimental Evaluation of Sinusoidal Leading Edges. J. of Aircraft, 2007.

[7] WEBER, P., HOWLE, L., MURRAY, M., MIKLOSOVIC, D.: Computational Evaluation of the Performance of Lifting Surfaces with Leading-edge Protuberances. J. of Aircraft, 2011.

[8] PEDRO, H., KOBAYASHI, M.: Numerical Study of Stall Delay on Humpback Whale Flippers. AIAA, 2008.

[9] CUSTODIO, D., JOHARI, H.: Aerodynamic Characteristics of Finite-span Wings with Leading Edge Protuberances. AIAA, 2012. 